06

\title{
Развитие модели спинодального распада на примере гетероструктуры на основе политипов карбида кремния
}

\author{
(C) С.Ю. Давыдов ${ }^{1,2}$, А.А. Лебедев ${ }^{1}$, С.П. Лебедев ${ }^{1}$, \\ А.А. Ситникова ${ }^{1}$, Л.М. Сорокин ${ }^{1}$ \\ ${ }^{1}$ Физико-технический институт им. А.Ф. Иоффре РАН, Санкт-Петербург \\ ${ }^{2}$ Санкт-Петербургский национальный исследовательский университет \\ информационных технологий, механики и оптики \\ E-mail: Sergei_Davydov@mail.ru
}

Поступило в Редакцию 8 августа 2016 г.

Исследована переходная область гетероструктуры $3 \mathrm{C}-\mathrm{SiC} / 4 \mathrm{H}-\mathrm{SiC}$, состоящая из слоев политипов $3 C$ и $4 H$. На основе предложенной ранее модели спинодального распада получена оценка соотношения толщин $4 H$ - и $3 C$-слоев в сопоставлении с наблюдаемой картиной, полученной с помощью просвечивающей электронной микроскопии.

Уникальной особенностью карбида кремния является политипизм, т.е. возможность кристаллизоваться в различных модификациях. Политипы $\mathrm{SiC}$, имея одинаковую химическую природу, могут значительно отличаться по своим электрофизическим параметрам. Наиболее интенсивно изучаются гетеропереходы между кубическим политипом карбида кремния $3 C$ - $\mathrm{SiC}$ и одним из гексагональных политипов $\mathrm{NH}$ $\mathrm{SiC}$, где $N=4,6$. Несмотря на то, что уже были сообщения о получении двумерного электронного газа на границе $3 C / 4 H$, HEMTтранзисторы до сих пор не созданы. По-видимому, это связано с недостаточной изученностью трансформации политипов в процессе гетерополитипной эпитаксии и наличием переходной области между $3 C$-слоем и $N H$-подложкой. Действительно, в работах $[1,2]$ в переходных слоях гетероперехода $3 C / 6 H$ была обнаружена структура, состоящая из чередующихся полос исходного и растущего политипов (квазисверхрешетка). Для объяснения наличия такой структуры там же была предложена модель специфического спинодального распада. 
Целью настоящей работы является развитие этой модели на примере гетероперехода $3 \mathrm{C}-\mathrm{SiC} / 4 H-\mathrm{SiC}$.

В соответствии с вакансионной моделью [3,4] каждый политип карбида кремния однозначно характеризуется концентрациями углеродных $N_{\mathrm{C}}$ и кремниевых $N_{\mathrm{Si}}$ вакансий. Процесс гетерополитипной эпитаксии представляет собой переход от концентраций $N_{1 \mathrm{C}}$ и $N_{1 \mathrm{Si}}$, характеризующих подложку, до концентраций $N_{2 \mathrm{C}}$ и $N_{2 \mathrm{Si}}$, характеризующих формирующийся политип. При этом за время $t_{T}$ от начала процесса эпитаксии образуется переходный слой толщиной $L_{T}$, скорость роста которого $G=L_{T} / t_{T}$.

Рассмотрим процесс роста $3 C$-политипа на $4 H$-подложке, в ходе которого должна увеличиваться концентрация углеродных вакансий от $N_{\mathrm{C}}^{4 H}=7.3 \cdot 10^{20} \mathrm{~cm}^{-3}$ до $N_{C}^{3 C}=23.5 \cdot 10^{20} \mathrm{~cm}^{-3}$ и уменьшаться концентрация кремниевых вакансий от $N_{\mathrm{Si}}^{4 H}=7.3 \cdot 10^{20} \mathrm{~cm}^{-3}$ до $N_{\mathrm{Si}}^{3 C}=2.0 \cdot 10^{20} \mathrm{~cm}[5]$. Как показано в [4], временные изменения концентраций вакансий даются выражениями

$$
\begin{aligned}
& N_{\mathrm{C}}(t)=N_{1 \mathrm{C}} \exp \left(t / \tau_{\mathrm{C}}\right), \\
& N_{\mathrm{Si}}(t)=N_{1 \mathrm{Si}} \exp \left(-t / \tau_{\mathrm{Si}}\right),
\end{aligned}
$$

где $\tau_{C}$ и $\tau_{\mathrm{Si}}$ - время жизни углеродных и кремниевых вакансий в переходном слое. Будем отсчитывать координату $z$ вдоль внешней нормали к поверхности подложки. Пусть толщина слоя, образовавшегося за время $t$, есть $z=G t$. Тогда выражения (1) могут быть переписаны в виде

$$
\begin{aligned}
& N_{\mathrm{C}}(z)=N_{1 \mathrm{C}} \exp \left(z / G \tau_{\mathrm{C}}\right), \\
& N_{\mathrm{Si}}(Z)=N_{1 \mathrm{Si}} \exp \left(-z / G \tau_{\mathrm{Si}}\right) .
\end{aligned}
$$

При этом за время $t_{T}$ от начала процесса эпитаксии образуется переходный слой толщиной $L_{T}$. Пусть теперь площадь растущего слоя равна $A$. Количество вакансий углерода и кремния, накопленных в переходном слое $L_{T}$, равны соответственно

$$
\begin{aligned}
& M_{\mathrm{C}}=A G \tau_{\mathrm{C}} N_{1 \mathrm{C}}\left[\exp \left(L_{T} / G \tau_{\mathrm{C}}\right)-1\right], \\
& M_{\mathrm{Si}}=A G \tau_{\mathrm{Si}} N_{1 \mathrm{Si}}\left[1-\exp \left(-L_{T} / G \tau_{\mathrm{Si}}\right)\right] .
\end{aligned}
$$

$5^{*}$ Письма в ЖТФ, 2016, том 42, вып. 23 
Так как $L_{T} / G \tau_{\mathrm{C}}=\ln \left(N_{2 \mathrm{C}} / N_{1 \mathrm{C}}\right)$ и $L_{T} / G \tau_{\mathrm{Si}}=\ln \left(N_{1 \mathrm{Si}} / N_{2 \mathrm{Si}}\right)$, отсюда

$$
\begin{aligned}
& M_{\mathrm{C}}=A L_{T} \rho_{\mathrm{C}}, \quad \rho_{\mathrm{C}}=\frac{N_{2 \mathrm{C}}-N_{1 \mathrm{C}}}{\ln \left(N_{2 \mathrm{C}} / N_{1 \mathrm{C}}\right)}, \\
& M_{\mathrm{Si}}=A L_{T} \rho_{\mathrm{Si}}, \quad \rho_{\mathrm{Si}}=\frac{N_{1 \mathrm{Si}}-N_{2 \mathrm{Si}}}{\ln \left(N_{1 \mathrm{Si}} / N_{2 \mathrm{Si}}\right)},
\end{aligned}
$$

где нижние индексы 1 и 2 относятся соответственно к $4 H$-подложке и $3 C$-слою. Таким образом, для рассматриваемого случая получаем $\rho_{\mathrm{C}} \approx 13.9 \cdot 10^{20} \mathrm{~cm}^{-3}$ и $\rho_{\mathrm{Si}} \approx 4.1 \cdot 10^{20} \mathrm{~cm}^{-3}$.

Для объяснения наличия полос различных политипов в переходной области в работах [1,2] было предположено, что имеет место специфический спинодальный распад $(\mathrm{CP})$. Действительно, при обычном СР рассматривается переход из пространственно-однородного состояния в периодическую пространственную структуру [6,7]. В нашей задаче начальное состояние является монотонной функцией координаты $z$. Поэтому прибегнем к упрощенному рассмотрению.

Пусть в переходном слое появляется $n_{i}$ полос политипа $i=1,2$ шириной $l_{i}$ и концентрацией вакансий $N_{i \mathrm{C}}, N_{i \mathrm{Si}}$. Тогда

$$
\begin{aligned}
& \xi_{1} N_{1}+\xi_{2} N_{2}=\rho, \\
& \zeta_{1}+\zeta_{2}=1,
\end{aligned}
$$

где $\xi_{i}=n_{i} l_{i} / L_{T}, N_{i}=N_{i \mathrm{C}}+N_{i \mathrm{Si}}$ и $\rho=\rho_{\mathrm{C}}+\rho_{\mathrm{Si}}$;

$$
\begin{aligned}
& \xi_{1}=\frac{N_{2}-\rho}{N_{2}-N_{1}}, \\
& \xi_{2}=\frac{\rho-N_{1}}{N_{2}-N_{1}} .
\end{aligned}
$$

Для рассматриваемого здесь случая $\xi_{1}=0.69$ и $\xi_{2}=0.31$. Для идеальной сверхрешетки, т. е. в отсутствие дефектов упаковки, $n_{1}=n_{2}=n$, так что $l_{i}=\xi_{i}\left(L_{T} / n\right)$, откуда

$$
\frac{l_{1}}{l_{2}}=\frac{N_{2}-\rho}{\rho-N_{1}}
$$

Таким образом, толщина $4 H$-полос должна превосходить толщину $3 C$-включений в $l_{1} / l_{2} \approx 2.2$ раза.

Письма в ЖТФ, 2016, том 42, вып. 23 
Таблица 1. Значения отношения $l_{1} / l_{2} \equiv l_{\text {substrate }} / l_{\text {layer }}$ для политипов карбида кремния

\begin{tabular}{c|c|c|c|c|c|c}
\hline \multirow{2}{*}{ Substrate } & \multicolumn{6}{|c}{ Layer } \\
\cline { 2 - 7 } & $3 C$ & $8 H$ & $6 H$ & $15 R$ & $27 R$ & $4 H$ \\
\hline $3 C$ & - & 0.9 & 0.8 & 0.7 & 0.6 & 0.5 \\
$8 H$ & 1.1 & - & 1.0 & 0.7 & 0.6 & 0.4 \\
$6 H$ & 1.3 & 1.0 & - & 1.0 & 0.7 & 0.6 \\
$15 R$ & 1.5 & 1.4 & 1.0 & - & 1.0 & 0.8 \\
$27 R$ & 1.8 & 1.8 & 1.5 & 1.0 & - & 0.8 \\
$4 H$ & 2.2 & 2.3 & 1.8 & 1.3 & 1.3 & -
\end{tabular}

Таблица 2. Толщины политипных слоев в переходной области гетероструктуры $3 C$ - $\mathrm{SiC} / 4 H$-SiC (нумерация слоев идет по направлению от $4 H$-подложки к эпитаксиальному $3 C$-слою, SF - дефекты упаковки)

\begin{tabular}{l|c|c|c|c|c}
\hline Stripe-No & $3 C(1)$ & $4 H(1)$ & $3 C(2)$ & $\mathrm{SF}$ & $3 C(3)$ \\
\hline Width, nm & 9 & 16 & 4 & $1-2$ & 8
\end{tabular}

Результаты аналитических расчетов для разных пар приведены в табл. 1, где представлены возможные соотношения толщин слоев в переходной области для различных сочетаний политипов при гетероэпитаксии карбида кремния.

Для получения экспериментальных данных эпитаксиальный слой $3 C$-SiC n-типа был выращен методом сублимации в вакууме [8] на коммерческой $4 H-\mathrm{SiC}$ подложке $n$-типа, предоставленной компанией CREE. Исследование интерфейса в гетероструктуре $3 C / 4 H$ проводилось с использованием электронных микроскопов JEOL 2100F и Philips EM420.

На рисунке представлен типичный пример переходной области для структуры $3 C / 4 H$, который характеризуется чередованием слоев этих политипов. Как правило, внутри переходной зоны встречаются различные варианты последовательности политипов, но вполне вероятно, что соотношение толщин слоев подчиняется определенным закономерностям. Изредка чередование бывает периодическим, напоми-

Письма в ЖТФ, 2016, том 42, вып. 23 


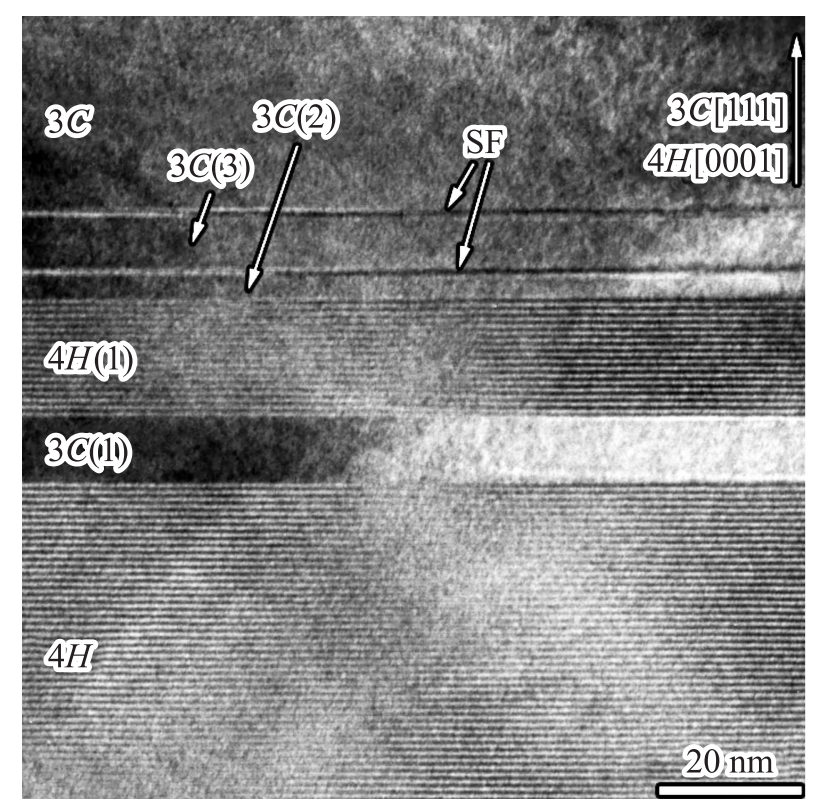

Изображение поперечного сечения гетероструктуры $3 C$ - $\mathrm{SiC} / 4 H-\mathrm{SiC}$, полученное методом просвечивающей электронной микроскопии.

ная сверхрешетку. На рисунке обозначены политипы наблюдаемых в данном случае слоев карбида кремния согласно картинам электронной дифракции. В слое $4 H(1)$ разрешаются атомные плоскости (см. рисунок) с межплоскостным расстоянием $\sim 10 \AA$, которые соответствуют параметру $c=10.053 \AA$ решетки политипа $4 H$. Узкие полосы, обозначенные на рисунке как SF, по нашему мнению, - дефекты упаковки в эпитаксиальном слое $3 C$-SiC [9]. Широкий слой со стороны подложки, обозначенный на рисунке как $4 H$, с разрешенными атомными плоскостями с межплоскостным расстоянием $\sim 10 \AA$ относится к политипу $4 H$-SiC. Результат анализа толщин видимых на изображении слоев представлен в табл. 2. Обратим внимание на слои $3 C(1)$ и $4 H(1)$. Отношение толщин $4 H(1) /(3 C)$ составляет 1.8 , что достаточно хорошо согласуется с расчетным отношением 2.2 (табл. 1). Вряд ли выявленное согласие расчетного значения отношения толщин $4 H(1) /(3 C)$ с экс-

Письма в ЖТФ, 2016, том 42, вып. 23 
периментальным для 4H(1)/3C(1) является случайным. В дальнейшем предполагается провести статистический анализ изображений переходного слоя для различных подложек, используемых при росте $3 C$ - $\mathrm{SiC}$ для полной адекватности расчетных отношений толщин слоев $N H / 3 C$ с экспериментальными. Для подложки $15 R$ эти отношения составляют от 1.5 и меньше, и только для $27 R$ величины этих отношений близки к таковым для подложки $4 H$.

Таким образом, в работе показано, что развитие вакансионной модели спинодального распада позволяет теоретически оценить отношение толщин политипов карбида кремния в переходном слое между подложкой и эпитаксиальным слоем. Удовлетворительное согласие расчета с экспериментом для слоев $4 H(1), 3 C(1)$ в переходной области свидетельствует о перспективности предложенной ранее вакансионной модели спинодального распада для гетероструктур на основе политипов карбида кремния.

Работа выполнена при частичной поддержке гранта РФФИ 14-0200552 „Получение и исследование сверхрешеток в системе кубическийгексагональный $\mathrm{SiC}^{\text {“ }}$ и на оборудовании Центра коллективного пользования „Материаловедение и диагностика в передовых технологиях“ ФТИ им. А.Ф. Иоффе, С.-Петербург.

\section{Список литературы}

[1] Лебедев А.А., Заморянская М.В., Давыдов С.Ю. и др. // ФТП. 2013. Т. 47. B. 11. C. $1554-1558$.

[2] Lebedev A.A., Zamoryanskaya M.V., Davydov S.Yu. et al. // J. Cryst. Growth. 2014. V. 395. N 1. P. $100-103$.

[3] Лебедев А.А., Давыдов С.Ю. // ФТП. 2005. Т. 39. В. 3. С. 296-299.

[4] Давыдов С.Ю., Лебедев А.А. // ФТП. 2007. Т. 41. В. 6. С. 641-644.

[5] Лебедев А.А. // ФТП. 1999. Т. 33. В. 7. С. 769-771.

[6] Хачатурян А.Г. Теория фазовых превращений и структура твердых растворов. М.: Наука, 1974. 384 с.

[7] Скрипов В.П., Скрипов А.В. // УФН. 1979. Т. 128. В. 6. С. 193-231.

[8] Лебедев А.А., Мосина Г.Н., Никитина И.П. и др. // Письма в ЖТФ. 2001. T. 27. B. 24. C. $57-63$.

[9] Lindefelt U., Iwata H. // Silicon Carbide. Recent Major Advances. / Ed. by Choyke W.J., Matsunami H., Pensl G. Berlin, Heidelberg: Springer, 2004. 899 p. http://www.springer.de

Письма в ЖТФ, 2016, том 42, вып. 23 